\title{
Misuse of pharmaceuticals by regular psychostimulant users is linked to mental health problems
}

\author{
Caroline L. Salom, ${ }^{1}$ Lucinda A. Burns, ${ }^{2}$ Rosa Alati ${ }^{1}$
}

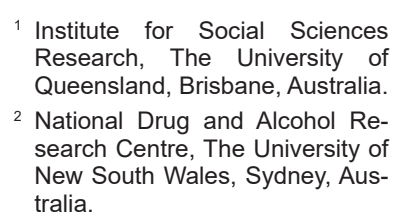

1 Institute for Social Sciences Research, The University of Queensland, Brisbane, Australia.

2 National Drug and Alcohol Research Centre, The University of New South Wales, Sydney, Australia.

Correspondence:

Caroline Salom

Institute for Social Science

Research, The University of

Queensland.

Long Pocket Precinct, 80 Meiers

Rd, Indooroopilly, Queensland 4068

Australia.

Phone: +61 425566 - 700

Email: c.salom@uq.edu.au

Received first version: October 9, 2017

Second version: October 18, 2017

Accepted: November 21, 2017

doi:10.17711/SM.0185-3325.2017.034

\begin{abstract}
Introduction. Misuse of pharmaceutical drugs, particularly by young people, is an issue of rising concern. Poly-substance use is common among regular psychostimulant users (RPU), and mental health problems are associated with pharmaceutical misuse, but RPU do not generally acknowledge their use as problematic. Objective. To examine links between mental health and misuse of non-prescription pharmaceuticals in a group of regular users of illicit psychostimulants. Method. Face to face structured interviews were conducted in April 2015 with 763 regular users of illicit psychostimulants as part of the Annual Ecstasy and Related Drugs Reporting System study in Australia. Results. At least half of the RPU in this study reported extra-medical or misuse of pharmaceuticals in the last six months in addition to regular use of illicit psychostimulants. Higher levels of psychological distress were recorded for RPU who also reported recent illicit use of opioids, antidepressants, benzodiazepines, or over-the-counter (OTC) codeine. Recent misuse of benzodiazepines or OTC codeine was associated with self-reported mental health problems and having attended a mental health professional. Those reporting recent misuse of opioids were at increased risk of mental health problems and more likely to record high levels of psychological distress, but less likely to have received prescription medications for their mental health problem. Discussion and conclusion. Regular users of illicit psychostimulants who also misuse pharmaceuticals are at increased risk of mental health problems, even after accounting for their use of illicit psychostimulants. Screening of this group for mental health problems is recommended.
\end{abstract}

Keywords: Non-prescription drugs, substance abuse, mental disorders, substance-related disorders, recreational drugs.

\section{RESUMEN}

Introducción. El uso indebido de psicofármacos, particularmente entre los jóvenes, es un tema de creciente preocupación. El policonsumo de sustancias es común entre los usuarios regulares de psicoestimulantes (URP), y, pese a que hay problemas de salud mental asociados con el uso indebido de medicamentos, los URP generalmente no reconocen su consumo como problemático. Objetivo. Examinar las relaciones entre la salud mental y el uso indebido de psicofármacos no prescritos en un grupo de URP. Método. Se realizaron entrevistas cara a cara con 763 URP como parte del Estudio Anual del Sistema de Reporte de Éxtasis y Drogas Relacionadas en Australia. Resultados. Al menos la mitad de los URP en este estudio informaron el uso extramédico o indebido de psicofármacos en los últimos seis meses, además del uso regular de psicoestimulantes ilícitos. Se hallaron niveles más altos de distrés psicológico para los URP, quienes también informaron de un uso ilícito reciente de codeína, opiáceos, antidepresivos o benzodiazepinas sin prescripción médica. El uso indebido reciente de codeína o benzodiazepinas sin prescripción se asoció a problemas autorreportados de salud mental y a asistencia a consulta con un profesional de salud mental. Aquellos que informaron el uso indebido reciente de opioides mostraron mayor riesgo de problemas de salud mental y mayor probabilidad de registrar altos niveles de distrés psicológico, pero menor probabilidad de haber recibido psicofármacos prescritos para su problema de salud mental. Discusión y conclusión. Los URP que también consumen indebidamente psicofármacos están en mayor riesgo de presentar problemas de salud mental, incluso después de considerar su consumo de psicoestimulantes ilícitos. Se recomienda una evaluación por tamizaje para problemas de salud mental en este grupo.

Palabras clave: Medicamentos sin receta, abuso de sustancias, trastornos relacionados con sustancias, uso indebido, drogas recreativas. 


\section{INTRODUCTION}

Against a background of increasing misuse of pharmaceuticals in Australia (Australian Government, 2012; Nicholas, Lee, \& Roche, 2011) and overseas (International Narcotics Control Board, 2016), particular concerns have been raised over misuse by young people (Lasopa, Striley, \& Cottler, 2015). In the US, attention has often focussed on the rise in illicit use of pharmaceutical opioids and other analgesics (Maxwell, 2011), but emergency responses linked to the misuse of substances, such as benzodiazepines, anti-convulsants, and antidepressants, have also risen significantly (Bachhuber, Maughan, Mitra, Feingold, \& Starrels, 2016; Lloyd \& McElwee, 2011). Although there are well-documented health issues associated with the misuse of each of these substances, further risks may be incurred when these substances interact with other drugs in an uncontrolled manner, such as increased likelihood of overdose and other adverse reactions. Additionally, mental health issues are more likely to be reported by poly-substance users (Salom, Betts, Williams, Najman, \& Alati, 2016). This places young adults, among whom poly-substance use is common (Connor, Gullo, White, \& Kelly, 2014), at a high risk. As such, groups who regularly use multiple substances are of public health concern (Bachhuber et al., 2016), despite many regarding their substance use as non-problematic.

Concern has been expressed about these risks in Australia (Lloyd \& McElwee, 2011; Nielsen \& Bruno, 2011), but few reports have been published on the levels of use among non-clinical populations (Dunlop, 2011), and most focus on a single class of substance or on prescription medications only (Nielsen \& Bruno, 2014). One recent study from New Zeland described a significant illicit use of a range of pharmaceuticals in a sample of regular drug users (Wilkins, Sweetsur, \& Griffiths, 2011). Other research in New South Wales highlighted a diversion of pharmaceutical stimulants (Kaye, Darke, \& Torok, 2014), however little is known about the risks associated with this type of use.

Here we report on mental health issues in a recent national sample of individuals who are regular psychostimulant users and typically report using multiple substances (Sindicich \& Burns, 2015). Our aim was to examine extra-medical or illicit use of pharmaceutical substances among a group of regular psychostimulant users (RPU) and to examine links between mental health problems and illicit pharmaceutical use.

\section{METHOD}

\section{Study design}

The Ecstasy and Related Drugs Reporting System (EDRS) study is a cross-sectional study conducted annually in each capital city of Australia since 2000, interviewing a sentinel population across a range of jurisdictions to understand rapidly emerging trends in patterns of use and associated health issues. A detailed description of the EDRS and its methodology may be found at http://www.drugtrends.org.au/ reports/national-report-2015-ecstasy-and-related-drugs-reporting-system-edrs/. The present study is a secondary analysis using data from the 2015 EDRS (Sindicich, Stafford, \& Breen, 2016).

\section{Participants}

We used a purposive sampling method which included posters in entertainment precincts, street press, targeted radio and internet advertisements, and word of mouth during April 2015. Potential participants contacted a central coordinator by telephone or email, who then established their eligibility and booked an interview time and location. People who reported regular use (at least monthly during the past six months) of illicit psychostimulants (i.e., ecstasy, cocaine, methamphetamine, LSD, or analogues of these), were eligible for the study. Those who were under sixteen years of age, who had not resided in the location for at the past 12 months, and those who regularly injected illicit substances were excluded. The 2015 sample used in this study comprised 763 regular psychostimulant users.

\section{Sites}

Participants were recruited and interviewed in the capital cities of each state/territory in Australia: Canberra, Sydney, Brisbane, Darwin, Melbourne, Adelaide, Perth, and Hobart.

\section{Measures}

Participants reported on the amount and frequency with which they used illicit drugs over the past six months, as well as illicit or extra-medical use (i.e., consumption of a substance not directly prescribed to the user, or for purposes other than the intended medical use) of pharmaceutical stimulants, over-the-counter (OTC) codeine, other opioids, benzodiazepines, antidepressants and antipsychotic medications.

Participants also reported whether they had experienced "any mental health problems" in the last six months, with the subsequent option to specify a problem (e. g., depression, anxiety, drug-related psychosis), and were assessed for symptoms of psychological distress using the Kessler-10 (K10) scale (Kessler \& Mroczek, 1994). This standardised 10-item scale has been found to have good psychometric properties and to identify clinical levels of psychological distress (as measured using the DSM) in the general population (Andrews \& Slade, 2001; Kessler et al., 2002), but has also been validated with drug using populations (Hides et al., 2007). 
Both total scores and a binary variable indicating high levels of psychological distress (K10 score over 21) were used (Hides et al., 2007). Participants also reported help seeking behaviour (having visited a mental health professional) and receipt of medication for mental health problems during the last six months, the latter used as a proxy for severity.

Demographic information was also collected for participants. We included the following factors as covariates due to their frequent links to mental health disorders or substance misuse: gender (not female/female); age (years); relationship status (not single/single); sexual identity (heterosexual/not heterosexual); employment (at least part time/less than part time); and education level (any tertiary qualification/no tertiary qualification).

\section{Procedures}

Structured, confidential, and anonymous interviews lasting approximately one hour were conducted face-to-face during April 2015 by trained research staff in a cafe convenient to the participant. Interviews yielded details of participants' patterns of drug use, associated health, social and justice-related issues, and involvement with local drug markets. Participants were compensated AUD40 for their participation. The confidential, anonymous, and voluntary nature of the interviews was explained to all participants, who were provided with an information sheet and then provided written consent before commencement of the interview.

\section{Statistical analyses}

Participants reporting misuse of each class of pharmaceutical were compared to those who did not use that pharmaceutical. Differences in group means (e. g., mean age or K10 scores) were assessed by paired t-tests. Chi-squared tests were used to assess differences in demographic characteristics for users of each class of pharmaceutical. Logistic regression analyses were used to assess relationships between recent use of each class of pharmaceutical and mental health indicators, other than the total K10 score, for which linear regression was used. Models were adjusted for demographic covariates listed above. In sensitivity analyses, models were further adjusted for frequency of illicit psychostimulant use. Analyses were conducted in Stata 13 (StataCorp, Texas, USA).

\section{Ethical considerations}

Ethics clearance for the national study was obtained from the University of New South Wales, and from the relevant committees for each state/territory sub-study.

\section{RESULTS}

Recent illicit or extra-medical use of pharmaceuticals was common in this sample: $51 \%$ reported extra-medical consumption of any pharmaceutical in the last six months (Table 1). The most commonly used were pharmaceutical stimulants $(31 \%$, including dexamphetamine, methylphenidate, and modafinil), benzodiazepines (27\%), opioids (10\%), and OTC codeine preparations (16\%). Those reporting misuse of opioids, benzodiazepines, and antipsychotics were more likely to be male than those who did not, stimulant users were more likely to be non-heterosexual than non-stimulant users, opioid and antidepressant users were more likely to be unemployed than those who did not use those substances, and OTC codeine users less likely to have a post-school qualification than non-OTC codeine users. Illicit use of pharmaceuticals was likely to have begun after the age of 18 and use of individual classes of pharmaceutical tended

Table 1

Characteristics of RPU who reported recent illicit use of pharmaceutical medications, 2015

\begin{tabular}{|c|c|c|c|c|c|c|c|c|c|}
\hline Substance type & $\begin{array}{c}\text { Prevalence } \\
(\%)\end{array}$ & $\begin{array}{c}\text { Mean age } \\
\text { years }\end{array}$ & $\begin{array}{c}\text { Female } \\
\%\end{array}$ & $\begin{array}{c}\text { Single } \\
\%\end{array}$ & $\begin{array}{c}\text { Non-hetero } \\
\%\end{array}$ & $\begin{array}{c}\text { Un-employed } \\
\%\end{array}$ & $\begin{array}{c}\text { Tertiary } \\
\text { qualified } \\
\%\end{array}$ & $\begin{array}{c}\text { Age } \\
\text { of initial use } \\
\text { Age (SD) }\end{array}$ & $\begin{array}{c}\text { Used } \geq \\
\text { monthly } \\
\%\end{array}$ \\
\hline All RPU & 100 & 22.7 & 37 & 63 & 13 & 27 & 47 & $17.8(2.8)$ & 100 \\
\hline Any pharmaceutical† & 51 & 22.3 & 34 & 64 & 14 & 29 & 47 & $\mathrm{n} / \mathrm{a}$ & $\mathrm{n} / \mathrm{a}$ \\
\hline Pharmaceutical stimulants & 31 & 22.1 & 33 & 67 & $17^{*}$ & 31 & 40 & $18.8(3.6)$ & 39 \\
\hline OTC codeine & 16 & 21.7 & 32 & 66 & 14 & 34 & $38^{*}$ & $19.0(3.6)$ & 37 \\
\hline Other opioids & 10 & 23.0 & $23^{*}$ & 65 & 10 & $41^{*}$ & 41 & $20.3(7.5)$ & 20 \\
\hline Benzodiazepines & 27 & 22.5 & $29^{*}$ & 64 & 13 & 30 & 47 & $19.7(3.9)$ & 37 \\
\hline Antidepressants & 1 & 21.0 & 21 & 73 & 27 & $55^{*}$ & 33 & $18.4(2.8)$ & 18 \\
\hline Antipsychotics & 3 & 22.0 & $15^{*}$ & 78 & 13 & 43 & 38 & $20.1(4.6)$ & 35 \\
\hline
\end{tabular}

Note: Age of initial use is the age at which psychostimulant use was reported to commence; Used $\geq$ monthly use refers to the frequency of use of any psychostimulant; Unemployed = employed less than part-time; Tertiary = completed a qualification after completing high school; All RPU = the total group of regular psychostimulant users comprising this sample; †Any pharmaceutical refers to pharmaceutical stimulants or OTC codeine or other opioids or benzodiazepines or antidepressants or antipsychotics; * indicates that $\chi^{2}$ test showed a significant difference $(p<.05)$ from the total sample for users of that substance for that characteristic. 
Table 2

Associations between recent illicit use of pharmaceuticals and mental health indicators in RPU

\begin{tabular}{|c|c|c|c|c|c|}
\hline Recent illicit use & $\begin{array}{l}\text { Self-reported } \\
\text { MH problem } \\
\text { OR }(95 \% \mathrm{Cl})\end{array}$ & $\begin{array}{c}\text { Attended } \\
\text { MH professional } \\
\text { OR }(95 \% \mathrm{Cl})\end{array}$ & $\begin{array}{c}\text { Received } \\
\text { prescription meds } \\
\text { OR }(95 \% \mathrm{Cl})\end{array}$ & $\begin{array}{c}\text { K10 total score } \\
\beta(\mathrm{SE})\end{array}$ & $\begin{array}{c}\text { K10 high distress } \\
\text { OR }(95 \% \mathrm{Cl})\end{array}$ \\
\hline Any pharmaceutical† & $1.50(1.10,2.04)$ & $1.49(1.03,2.15)$ & $.81(.58,1.14)$ & $1.15(.51)^{\star}$ & $1.21(.88,1.66)$ \\
\hline Stimulants & $1.15(.82,1.59)$ & $1.07(.73,1.58)$ & $.97(.67,1.39)$ & $.80(.52)$ & $1.18(.84,1.65)$ \\
\hline OTC codeine & $1.57(1.04,2.36)$ & $2.01(1.27,3.17)$ & $1.21(.75,1.95)$ & $1.35(.66)^{*}$ & $1.20(.79,1.83)$ \\
\hline Other opioids & $1.96(1.20,3.20)$ & $1.68(.96,2.94)$ & $.56(.32, .97)$ & $1.63(.75)^{*}$ & 1.77 (1.08. 2.89) \\
\hline Benzodiazepines & $1.44(1.02,2.03)$ & $1.55(1.04,2.31)$ & $.95(.65,1.39)$ & $1.22(.54)^{*}$ & $1.20(.85,1.71)$ \\
\hline Antidepressants & $1.28(.36,4.51)$ & $.65(.13,3.30)$ & $.51(.15,1.78)$ & $1.34(2.01)$ & $2.21(.63,7.73)$ \\
\hline Antipsychotics & $.79(.26,2.41)$ & $1.64(.53,4.99)$ & $1.26(.41,3.86)$ & $3.27(1.99)$ & $.60(.20,1.82)$ \\
\hline
\end{tabular}

Note: $\mathrm{MH}=$ mental health; $\mathrm{K} 10=$ Kessler 10 scale of psychological distress: High distress $=\mathrm{K} 10>21$; †Any pharmaceutical refers to pharmaceutical stimulants or OTC codeine or other opioids or benzodiazepines or antidepressants or antipsychotics; Use of each pharmaceutical was modelled separately for each mental health indicators (i.e. each cell above represents a separate model); all models were adjusted for age, gender, sexual identity, unemployment and frequency of ecstasy/related drug use; ${ }^{*} p<.05$.

to be less than monthly. Those who reported recent misuse of any of the above pharmaceuticals, used psychostimulants more frequently ( $p<.01$, data not shown) compared to those who did not.

Over one-third $(36 \%)$ of RPU in this sample reported having experienced a mental health problem during the previous six months. After accounting for demographic factors, this was more likely for those who had recently misused opioids, benzodiazepines, or OTC codeine (Table 2). Those who had misused benzodiazepines or OTC codeine were also more likely to have attended a $\mathrm{MH}$ professional during the last six months (OR 1.55; 95\% CI $=1.04$, 2.31 and $\mathrm{OR} 2.01 ; 95 \% \mathrm{CI}=1.27,3.17$, respectively). Of those receiving medications for their $\mathrm{MH}$ problem, most prescriptions were for antidepressants (70\%). Other medications included benzodiazepines (28\%), antipsychotics $(14 \%)$, mood stabilizers $(8 \%)$, and stimulants $(6 \%)$. Total Kessler 10 scores were significantly increased for RPU who reported recent illicit use of OTC codeine $(\beta=1.35$; $\mathrm{SE}=.66)$, opioids $(\beta=1.63$; $\mathrm{SE}=.75)$ and benzodiazepines $(\beta=1.22$; $\mathrm{SE}=.54)$, but not for those who reported misusing antidepressants, antipsychotics or pharmaceutical stimulants. High or very high distress $(\mathrm{K} 10>21)$ was sig- nificantly more likely among those who had recently misused opioids (OR 1.77; 95\% CI $=1.08,2.89$ ) than those who had not. Adjustment of these relationships for frequency of psychostimulant use did not account for these relationships (Supplementary Table 1). Small sample size precluded the assessment of potential links between frequency of illicit antidepressant use and receipt of medications for mental health problems.

\section{DISCUSSION AND CONCLUSION}

The overall prevalence of pharmaceutical misuse is high $(51 \%)$ in this sample of regular psychostimulant users, with significant increases in the use of pharmaceutical stimulants and OTC codeine compared to reports in the previous year ( $p<.05$ for both) (Sindicich \& Burns, 2015). It is also higher than for the general Australian population, where among 20-29 year olds (the closest group in age to this sample) only $5.7 \%$ reported illicit use of any pharmaceutical in the past year (Australian Institute of Health and Welfare, 2017). The use of individual pharmaceuticals by our RPU tended to be less than monthly, which was similar to use by the

Supplementary Table 1

Associations between recent illicit use of pharmaceuticals and mental health indicators in RPU, adjusted for frequency of illicit psychostimulant use

\begin{tabular}{|c|c|c|c|c|c|}
\hline Recent illicit use & $\begin{array}{l}\text { Self-reported } \\
\text { MH problem } \\
\text { OR }(95 \% \mathrm{Cl})\end{array}$ & $\begin{array}{c}\text { Attended } \\
\text { MH professional } \\
\text { OR }(95 \% \mathrm{Cl})\end{array}$ & $\begin{array}{c}\text { Received } \\
\text { prescription meds } \\
\text { OR }(95 \% \mathrm{Cl})\end{array}$ & $\begin{array}{c}\text { K10 total score } \\
\beta(\mathrm{SE})\end{array}$ & $\begin{array}{c}\text { K10 high distress } \\
\text { OR }(95 \% \mathrm{Cl})\end{array}$ \\
\hline Any pharmaceutical & $1.66(1.18,2.34)$ & $1.69(1.12,2.54)$ & $1.95(1.12,3.41)$ & $1.30(.56)^{*}$ & $1.26(.89,1.77)$ \\
\hline Stimulants & $1.24(.86,1.78)$ & $1.17(.77,1.79)$ & $1.32(.76,2.29)$ & $.86(.71)$ & $1.14(.79,1.64)$ \\
\hline OTC codeine & $1.50(.97,2.37)$ & $1.93(1.16,3.19)$ & $3.04(1.68,5.50)$ & $1.34(.73)$ & $1.19(.75,1.89)$ \\
\hline Benzodiazepines & $1.60(1.10,2.33)$ & $1.71(1.11,2.63)$ & $2.10(1.21,3.65)$ & $1.15(.56)^{*}$ & $1.19(.81,1.74)$ \\
\hline Other opioids & $2.14(1.27,3.61)$ & $1.72(.96,3.14)$ & $2.54(1.22,5.29)$ & $1.97(.54)^{*}$ & $1.95(1.16,3.27)$ \\
\hline Antidepressants & $1.11(.28,4.38)$ & $.80(.15,4.27)$ & - & $1.31(.89)$ & $2.02(.55,7.50)$ \\
\hline Antipsychotics & $8.39(2.00,35.12)$ & $12.00(3.02,47.73)$ & $55.54(9.17,336.1)$ & $3.06(2.14)$ & $2.83(.82,9.72)$ \\
\hline
\end{tabular}

Note: $\mathrm{MH}=$ mental health; $\mathrm{K} 10=$ Kessler 10 scale of psychological distress: High distress = K10 > 21; Use of each pharmaceutical was modelled separately for each mental health indicators (i.e. each cell above represents a separate model); all models were adjusted for age, gender, sexual identity, unemployment and frequency of illicit psychostimulant (ecstasy/related drug) use; ${ }^{*} p<.05$. 
general population (54\% used less than monthly) (Australian Institute of Health and Welfare, 2017), but less frequent than their use of ecstasy tablets, and was linked to more frequent use of ecstasy and other illicit psychostimulants.

Even after accounting for stressors such as unemployment, non-heterosexual identity, and un-partnered relationship status that are frequently associated with mental health problems in this sample, participants reporting extra-medical use of pharmaceuticals appear to be at heightened risk of a range of mental health problems and increased levels of psychological distress. These problems may be severe, as suggested by greater attendance at mental health professionals. Receipt of mental health medication was not significantly related to misuse of the pharmaceuticals, and the pattern of medications received did not align with those misused, suggesting that the visits to $\mathrm{MH}$ professionals were not likely to be "doctor shopping" for illicit use (Maxwell, 2011; Worley, 2012). These potential harms were not accounted for by increased frequency of psychostimulant use, suggesting there may be a role in the mental health problems that is specific to the polypharmacy reported by regular "recreational" drug users (Kelly, Wells, Pawson, LeClair, \& Parsons, 2014; Smith, Farrell, Bunting, Houston, \& Shevlin, 2011; Wilkins et al., 2011).

Those who regularly use psychoactive substances, such as ecstasy and related drugs, tend not to view their illicit substance use as problematic, typically not seeking help from treatment professionals, and may view use of commercially formulated pharmaceuticals as less risky again, particularly given the occasional nature of the use as reported here. Despite this, the increased likelihood of mental health problems from the combination of substances is evident from our findings and those of some others (Lubman, Allen, Rogers, Cementon, \& Bonomo, 2007; Medina \& Shear, 2007), but is recognised as a gap in the overall literature (Kaye \& Darke, 2012).

This study provides a unique insight into patterns of mental health among regular psychostimulant users who also misuse pharmaceuticals, but must be considered in light of some limitations. The study uses a sentinel non-representative sample drawn from jurisdictions across the country, providing information from a range of contexts, and use of this sentinel population of regular psychostimulant users provides timely information on the emergence of new trends and emerging potential harms that is not possible from larger nationally-representative studies. Thus, generalisation of our findings must be undertaken with some caution. Additionally, although our sample is based in Australia, similar patterns of psychostimulant use exist among young people in many countries, and the emergence of pharmaceutical misuse is worldwide (International Narcotics Control Board, 2016). Our mental health indicators are not clinical, and so cannot provide mental health diagnoses, but they do provide a measure of distress and indi- cations of the severity of problems experienced by participants, with the Kessler 10 scale well characterised in drug using populations (NSW Government, 2015). Likewise, our measures of substance use rely on self-report, but these have been found to be robust among substance-using populations where data collection methodologies have appropriately addressed issues of anonymity and confidentiality (Queensland Government, 2017).

In conclusion, our findings shed light on the potential harms associated with the emerging issue of pharmaceutical misuse in a group of substance users who do not generally consider their use as problematic, and so may not interact with substance use treatment services. Mental health service providers should consider screening for extra-medical pharmaceutical misuse, particularly in patients such as young adults who are likely to use psychostimulants. Policy makers should also be aware of the potential link between extra-medical use of pharmaceuticals, including non-prescription medications, and mental health problems. Further research should also investigate links between intensity of illicit pharmaceutical use and mental health problems in regular users of psychostimulants.

\section{Funding}

The EDRS project is supported by funding from the Australian Government under the Substance Misuse Prevention and Service Improvement Grants Fund (RG123582). The funding source played no part in the study design, analysis, or decision to submit the paper for publication.

\section{Conflicts of interest}

The authors declare they have no conflicts of interest.

\section{Acknowledgements}

The authors would like to acknowledge researchers from the following institutions who contributed to the data collected for this study: Macfarlane Burnet Institute for Medical Research and Public Health, National Drug Research Institute and the University of Tasmania, and particularly Dr. Paul Dietze for helpful comments on the manuscript. Importantly, we would like to thank the regular ecstasy users who were willing to be interviewed and share their experiences.

\section{REFERENCES}

Andrews, G., \& Slade, T. (2001). Interpreting scores on the Kessler Psychological Distress Scale (K10). Australian and New Zealand Journal of Public Health, 25(6), 494-497.

Australian Government. (2012). National Pharmaceutical Drug Misuse Framework for Action (2012-2015). Canberra: Australian Government.

Australian Institute of Health and Welfare. (2017). National Drug Strategy Household Survey 2016: Detailed Findings Drug Statistics. Canberra: Australian Institute of Health and Welfare.

Bachhuber, M. A., Maughan, B. C., Mitra, N., Feingold, J., \& Starrels, J. L. (2016). Prescription monitoring programs and emergency department visits involving benzodiazepine misuse: Early evidence from 11 United States metropolitan areas. International Journal of Drug Policy, 28, 120-123. doi: 10.1016/j.drugpo.2015.08.005 
Connor, J. P., Gullo, M. J., White, A., \& Kelly, A. B. (2014). Polysubstance use: diagnostic challenges, patterns of use and health. Current Opinion in Psychiatry, 27(4), 269-275. doi: 10.1097/yco.0000000000000069

Dunlop, A. (2011). Harms: How much, how many, how often? Drug and Alcohol Review, 30(3), 332-333. doi: 10.1111/j.1465-3362.2011.00286.x

Hides, L., Lubman, D. I., Devlin, H., Cotton, S., Aitken, C., Gibbie, T., \& Hellard, M. (2007). Reliability and Validity of the Kessler 10 and Patient Health Questionnaire among Injecting Drug Users. Australian \& New Zealand Journal of Psychiatry, 41(2), 166-168. doi:10.1080/00048670601109949

International Narcotics Control Board. (2016). Availability of Internationally Controlled Drugs: Ensuring adequate access for medical and scientific purposes. New York: United Nations.

Kaye, S., \& Darke, S. (2012). The diversion and misuse of pharmaceutical stimulants: what do we know and why should we care? Addiction, 107(3), 467-477. doi: 10.1111/j.1360-0443.2011.03720.x

Kaye, S., Darke, S., \& Torok, M. (2014). Diversion and misuse of pharmaceutical stimulants among illicit drug users. Addiction Research \& Theory, 22(2), 109116. doi: 10.3109/16066359.2013.779677

Kelly, B. C., Wells, B. E., Pawson, M., LeClair, A., \& Parsons, J. T. (2014). Combinations of prescription drug misuse and illicit drugs among young adults. Addictive Behaviors, 39(5), 941-944. doi: 10.1016/j.addbeh.2013.12.003

Kessler, R., \& Mroczek, D. (1994). Final version of our Non-specific Psychological Distress Scale. Ann Arbor: Survey Research Centre of Institute for Social Research, University of Michigan.

Kessler, R. C., Andrews, G., Colpe, L. J., Hiripi, E., Mroczek, D. K., Normand, S.-L. T., ... \& Zaslavsky, A. M. (2002). Short screening scales to monitor population prevalences and trends in non-specific psychological distress. Psychological Medicine, 32(6), 959-976.

Lasopa, S. O., Striley, C. W., \& Cottler, L. B. (2015). Diversion of prescription stimulant drugs among 10-18-year-olds. Current Opinion in Psychiatry, 28(4), 292.

Lloyd, B. K., \& McElwee, P. R. (2011). Trends over time in characteristics of pharmaceutical drug-related ambulance attendances in Melbourne. Drug and Alcohol Review, 30(3), 271-280. doi: 10.1111/j.1465-3362.2011.00292.x

Lubman, D. I., Allen, N. B., Rogers, N., Cementon, E., \& Bonomo, Y. (2007). The impact of co-occurring mood and anxiety disorders among substance-abusing youth. Journal of Affective Disorders, 103(1-3), 105-112. doi: 10.1016/j. jad.2007.01.011

Maxwell, J. C. (2011). The prescription drug epidemic in the United States: A perfect storm. Drug and Alcohol Review, 30(3), 264-270. doi: 10.1111/j.14653362.2011.00291.x
Medina, K. L., \& Shear, P. K. (2007). Anxiety, depression, and behavioral symptoms of executive dysfunction in ecstasy users: Contributions of polydrug use. Drug and Alcohol Dependence, 87(2-3), 303-311. doi: 10.1016/j.drugalcdep.2006.09.003

Nicholas, R., Lee, N., \& Roche, A. M. (2011). Pharmaceutical Drug Misuse in Australia: Complex Problems, Balanced Responses. Adelaide: National Centre for Education and Training on Addiction.

Nielsen, S., \& Bruno, R. (2011). Pharmaceutical drugs: The delicate balance between reducing pain and reducing harm. Drug and Alcohol Review, 30(3), 233-235. doi: 10.1111/j.1465-3362.2011.00326.x

Nielsen, S., \& Bruno, R. (2014). Implementing real-time prescription drug monitoring: Are we ready? Drug and Alcohol Review, 33(5), 463-465. doi: 10.1111/ dar. 12195

NSW Government. (2015). Strengthening mental health care in NSW. Sydney: NSW Health.

Queensland Government. (2017). Chief Psychiatrist Policy: The treatment and care of patients. Brisbane: Queensland Health.

Salom, C. L., Betts, K. S., Williams, G. M., Najman, J. M., \& Alati, R. (2016). Predictors of comorbid polysubstance use and mental health disorders in young adults - a latent class analysis. Addiction, 111(1), 156-164. doi: 10.1111/ add. 13058

Sindicich, N., \& Burns, L. (2015). Australian trends in ecstasy and related drug markets 2014: Findings from the Ecstasy and Related Drugs Reporting System (EDRS). Sydney: National Drug and Alcohol Research Centre.

Sindicich, N., Stafford, J., \& Breen, C. (2016). Australian Trends in Ecstasy and related Drug Markets 2015. Findings from the Ecstasy and Related Drugs Reporting System (EDRS). Sydney: National Drug and Alcohol Research Centre.

Smith, G. W., Farrell, M., Bunting, B. P., Houston, J. E., \& Shevlin, M. (2011). Patterns of polydrug use in Great Britain: Findings from a national household population survey. Drug and Alcohol Dependence, 113(2-3), 222-228. doi: doi: 10.1016/j.drugalcdep.2010.08.010

Wilkins, C., Sweetsur, P., \& Griffiths, R. (2011). Recent trends in pharmaceutical drug use among frequent injecting drug users, frequent methamphetamine users and frequent ecstasy users in New Zealand, 2006-2009. Drug and Alcohol Review, 30(3), 255-263. doi: 10.1111/j.1465-3362.2011.00324.x

Worley, J. (2012). Prescription drug monitoring programs, a response to doctor shopping: Purpose, effectiveness, and directions for future research. Issues in Mental Health Nursing, 33(5), 319-328. doi: 10.3109/01612840.2011.654046 